\title{
The Effect of Enzymatic Pre-Treatment in Agarwood Oil Extraction
}

\author{
Astri Fadhilah Abdul Rahim ${ }^{\# 1}$, Atikah Kadri ${ }^{\# 2}$, Nor Masliyah Harun ${ }^{\# 3}$ \\ ${ }^{\#}$ Faculty of Chemical Engineering, Universiti Teknologi MARA, 40450 Shah Alam, Selangor Darul Ehsan, Malaysia

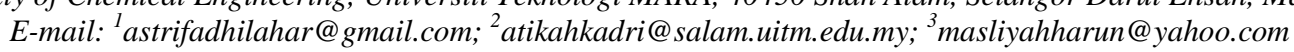

\begin{abstract}
Agarwood oil was extracted from a pre-treated agarwood chip soaked in a specific enzyme concentration of $1 \%, 3 \%$ and $5 \%$ respectively. The effect of soaking time was also investigated by applying soaking period in the range of 3 to 14 days. Hydrodistillation was carried out using the Clevenger-type apparatus to obtain the essential oil of agarwood chips. Subsequently the quality of the oil and the identification of its oil compounds were analyzed using GC-MS. The morphology of agarwood chips prior to hydrodistillation was characterized using scanning electron microscope (SEM). The SEM results of enzymatic pre-treated sample showed an obvious change in the cell morphology as compared to the sample with standard soaking of 6 days. The highest yield of oil with the amount of $0.125 \%$ is produced from the sample pre-treated with $3 \%$ enzyme concentration as compared to $0.065 \%$ of oil yield from the non-pre-treated sample employing similar soaking days. The GC-MS analysis revealed a total of 335 compounds from all samples of agarwood oil and similar compounds were found in the standard soaking and enzymatic pre-treated samples. Caryophyllene, Gurjunene, and Alloaromadendrene that contributes to the unique odour of agarwood oil are found mostly in all samples. Thus, the enzymatic pre-treatment indicates a comparable yield and oil quality and it is achievable even with a reduced soaking time of 6 days as compared to standard 14 days.
\end{abstract}

Keywords — agarwood; essential oil; enzymatic pre-treatment; GC-MS; hydrodistillation extraction.

\section{INTRODUCTION}

The essential oil has been widely used for centuries primarily for medicine but has since expanded into fragrance, food, pharmaceutical [1] and also in the agricultural, hygienic, and cosmetic industries [2]. It is a complex mixture of volatile to semi-volatile components where they generally have strong odor [3] and according to Costa et al.[4], essential oils are an aromatic and natural complex of mixtures of volatiles extracted from various plants as secondary metabolites. Najafian et al. [1] stated that essential oil could be extracted from different parts of plants such as flowers, roots, barks, leaves, etc.

Agarwood, also known locally as gaharu, is the fragrant resin produced primarily by the Aquilaria species (family: Thymelaeceae) and is highly valuable non-timber forest product and is high in demand globally [5]. It is also known by the name of Oudh, Chen Xiang and Eagleswood [6]. A few well-known agarwood-producing trees in the Thymelaeceae family are A. agallocha, A. crassna, A. bailloni, and A. Grandiflora [7]. This resin is produced when the trees are unhealthy as a self-defense mechanism in which it can occur both naturally and/or through wounding or artificially treated with inoculation.

Some of the isolated major contributing constituents to the aromatic smell of Agarwood are the three fragrant sesquiterpenes which are agarofuran, (-)-10-epi- $\gamma$-eudesmol and agarospirol [8]. The fragrant resin is usually used as perfumes, incense in religious ceremonies, and traditional medicines. Alam et al. [9] reported that Aquilaria agallocha leaves extract can be used as a laxative and some of its other beneficial properties are antimicrobial, antioxidant and antidiabetic.

Hydrodistillation is mostly applied by the commercial agarwood industries in Malaysia; even though this method is the simplest method, it is not effective in term of both timeand energy-consumption. The conventional method has major drawbacks in the operating process where the soaking may take 7 to 14 days [10] and another 4 to 10 days for the extraction completion. The long extraction times may influence the loss of some volatile fragrance constituents caused by the thermal degradation resulting in low oil yield [11], [12]. Thus, alternative methods such as introductions of pre-treatments steps to increase the yield and reduce soaking time have been extensively studied.

According to Puri et al. [13], enzyme-assisted extraction is gaining more attention as researchers seeks for ecofriendly extraction technologies and it was also mentioned that the application of enzymes increases the effect of solvent pre-treatment by either reducing the amount needed or increasing the extraction yield. A study by Dina et al. [14] further proved that enzyme-assisted extraction has the potential to improve the yield while maintaining bioactive 
properties of the extracts. Baby and Ranganathan [15] reported that this method of extraction is a recent approach in plants' bio-ingredients extraction where it is applied in the extraction of essential oils from seeds such as corn, sunflower, soybean and etc. but there is less studies done for agarwood oil extraction.

Other research has also shown that enzymatic pretreatment can achieve a high yield of extraction of oils, flavors, and medicinal compounds [16]. A study done in a uniform concentration to compare the effect of different enzyme shows that cellulase afforded the highest yield of essential oil of Fructus forsythia [17] and is consistent with our findings. The enzyme-assisted extraction improved the efficiency of extraction attributing to the destruction of the cell wall components [18]. Boulila et al. [19] in their study stated that the enzyme pre-treatment did not induce transformation of the volatile components in bay leaves (Laurus nobilis L.) but contributed to the release of some glycosidically bound volatiles which enhanced the release of phenolic compounds.

In research by Yoswathana [20], which is followed closely, the agarwood is treated with a combination method of both chemical and biological pre-treatment method where it is first treated with $1 \% \mathrm{H}_{2} \mathrm{SO}_{4}$ acid before the enzymatic treatment. Dimaki et al. [21] in their recent study showed the synergy between the combination of acidic and enzymatic pre-treatment which is a significant attribution to the high oil yield for Sideritis spp.. Thus, this research is done to investigate the effect of enzymatic pre-treatment with different enzyme concentration and incubation time on the yield of agarwood essential oil and to identify and compare the chemical compositions of oil extracted.

\section{THE MATERIAL AND METHOD}

\section{A. Materials}

Grounded agarwood chips were obtained from a Biobenua Lojistik Sdn. Bhd., a local agarwood plantation in Melaka. N-hexane and Sodium Hydroxide were bought from R\&M Chemicals, Malaysia. Sulfuric acid and Anyhydrous sodium sulfate were bought from JT Baker, USA and Merck, Germany respectively and Cellulose from Trichoderma reesei was bought from Sigma-Aldrich, USA.

\section{B. Materials Preparation}

1) Standard Preparation of Sample: The process for standard preparation of sample is adopted from a local agarwood processing company, Biobenua Lojistik Sdn. Bhd. $200 \mathrm{~g}$ of the grounded agarwood chips is first weighed and mixed with deionized water by a 1:10 ratio volume of water to weight of sample (v/w). The sample is left to soak for 14 days in room temperature. Standard sample will be named as S6 and S14 for sample soaked for 6 days and 14 days respectively.

2) Preparation of Sample with Acid: $200 \mathrm{~g}$ of grounded agarwood is measured and transferred into an Erlenmeyer flask. The agarwood chip is first treated with $2000 \mathrm{~mL}$ of $1 \%$ Sulphuric Acid $\left(\mathrm{H}_{2} \mathrm{SO}_{4}\right)$ and then autoclaved at $121{ }^{\circ} \mathrm{C}$ for 15 minutes as to breakdown the hemicellulose. The sample is then incubated at $55{ }^{\circ} \mathrm{C}$ for 6 days. Sample from this pretreatment is named as $\mathrm{AO}$.

3) Preparation of Sample with Enzymatic Pre-treatment: Agarwood chip that was prepared according to section B (2) is allowed to cool down after the autoclave process completed. Sodium Hydroxide $(\mathrm{NaOH})$ is added to adjust the $\mathrm{pH}$ of the solution to 4.8 and then mixed with cellulose enzyme with different concentration of 1,3 and $5 \%(\mathrm{w} / \mathrm{w})$ and followed by incubation for six days at $55{ }^{\circ} \mathrm{C}$. The pretreated sample with 1, 3, and $5 \%(\mathrm{w} / \mathrm{w})$ is known as EP1, EP3, and EP5 respective of their concentration. The sample will be further investigated with three days incubation time with the same parameter once the best enzyme concentration has been found and will be named respective of the best concentration.

4) Preparation of Sample with Enzyme: Acetate buffer is prepared where the $\mathrm{pH}$ of the buffer is adjusted to 4.8 before the addition of $3 \%$ cellulase enzyme. $200 \mathrm{~g}$ of grounded agarwood is soaked in the prepared solution and incubated in a water bath at $55{ }^{\circ} \mathrm{C}$ for six days. Sample for this pre-treatment is noted as EO.

\section{Hydrodistillation}

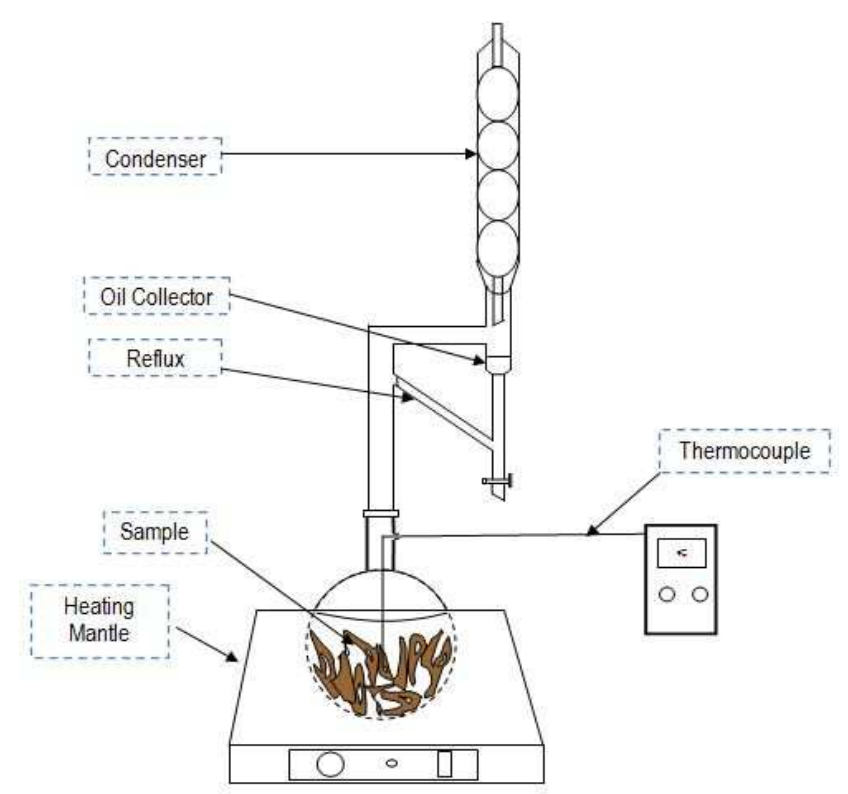

Fig. 1 Schematic Diagram

All samples prepared in sub-section B will undergone hydrodistillation using the Clevenger-type apparatus as shown in the schematic diagram in figure 1 . The temperature during the process is kept at $100 \pm 0.1{ }^{\circ} \mathrm{C}$. Oil formation is observed every 1 hour for a duration of 7 hours. The oil extracted will be collected and the moisture is removed by using anhydrous sodium sulfate and stored at $4{ }^{\circ} \mathrm{C}$ prior further analysis.

\section{Characterization of Agarwood Oil}

1) Gas Chromatography-Mass Spectrometer (GC-MS): GC-MS (QP 2010 series) was used to analyze chemical compounds from the extracted agarwood oil. The GC-MS is equipped with a VF-5ms fused silica capillary column and 
ionization energy of $70 \mathrm{eV}$ was used for the GC-MS detection. Helium gas $(99.99 \%)$ at a constant flow rate of 1 $\mathrm{mL} / \mathrm{min}$ was used as the carrier gas. The temperature for the oven was set at $50-230{ }^{\circ} \mathrm{C}$ at an increasing rate of $5{ }^{\circ} \mathrm{C} / \mathrm{min}$ and the injector temperature was set at $230{ }^{\circ} \mathrm{C}$. The peaks from GC-MS were identified using National Institute of Standards and Technology (NIST) mass spectral library.

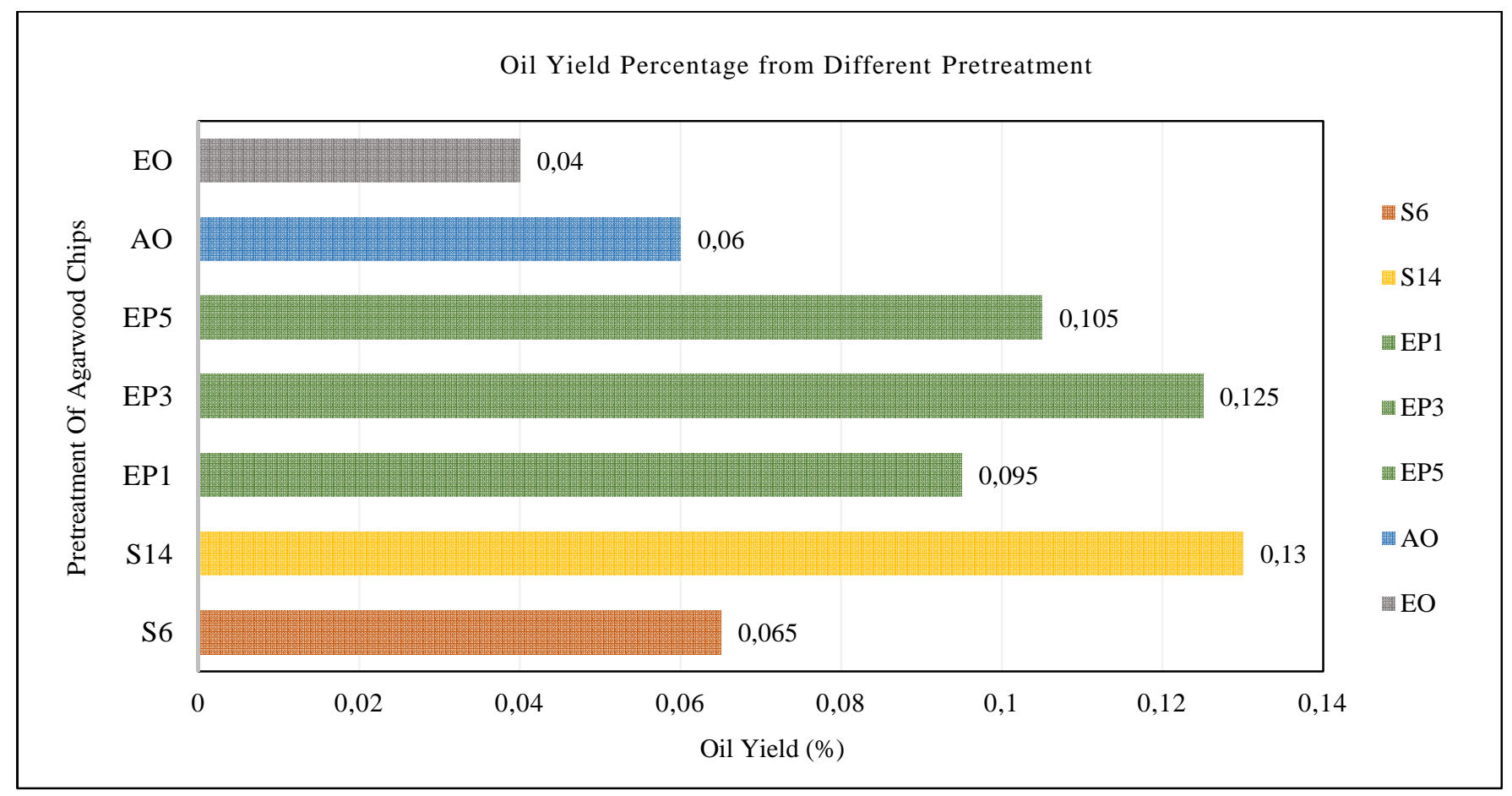

Fig. 2 Comparison on The Percentage of Agarwood Oil Yield with Different Pre-treatment.

2) Scanning Electron Microscope (SEM): The evaluation of the agarwood cell structure characteristics for all samples were done using a Scanning Electron Microscope (SEM). The cell structures were observed at 500 times magnification. The samples were coated with a layer of gold $(\mathrm{Au})$ to enhance the captured image using the mini Sputter Coater (Quorum Technologies, SC7620) and followed by SEM imaging using Hitachi Tabletop Microscope (TM-3000).

\section{RESULTS AND DISCUSSION}

\section{A. Effect of Pre-Treatment on Agarwood Oil Yield}

The effect of different pre-treatment on the yield of agarwood oil is summarized in figure 2. The percentage of oil yield for S14 is higher compare to S6, which is $0.13 \%$ and $0.065 \%$ respectively, where this supports the data provided by the local company where longer soaking time produced higher oil yield. A study done by Jok et al. [22] showed that agarwood chips that were soaked for 14 days have the highest yield however, further soaking time will only reduce the oil yield. As the soaking time increased, the acidity of the medium increases too as to corrode the cell wall of the agarwood chips, but over time, it may cause excessive breakage and releasing the chemical compounds to the soaking medium [23]. Further research by Jok et al. [24] confirmed that longer soaking time might increase the yield but over soaking will somehow give a lower yield which can result in the wastage of the essential compounds of the agarwood chips into the soaking water.

Figure 2 also shows that EP3 has the highest yield of $0.125 \%$, which is close to oil yield obtained from sample $\mathrm{S} 14$, which is $0.13 \%$. AO has a yield of $0.06 \%$, and EO sample has the lowest yield of $0.04 \%$ as shown in figure 2 . This proved that acid pre-treatment is necessary to increase enzyme-to-cellulose accessibility to increase the oil yield of agarwood through the degradation of the resin's cell wall material. This is supported by Chen et al. [25], where during the dilute acid pre-treatment, hemicellulose bond is removed thus the increase of the sample porosity which subsequently improves the enzymatic digestibility of cellulose and Van Dyk and Pletschke [26] also reported that by the degradation of hemicellulose which acts as physical barriers that hamper the access of cellulose to cellulose may increase the release of essential oil. The increase in the extraction yield was observed with enzyme concentration up to $3 \%$ but no substantial increase observed for enzyme concentration of $5 \%$ which is supported by Baby and Ranganathan [15] in their study where the increase of yield of essential oil was observed up to $1 \%$ of enzyme concentration and no corresponding significant increase for higher concentration. 


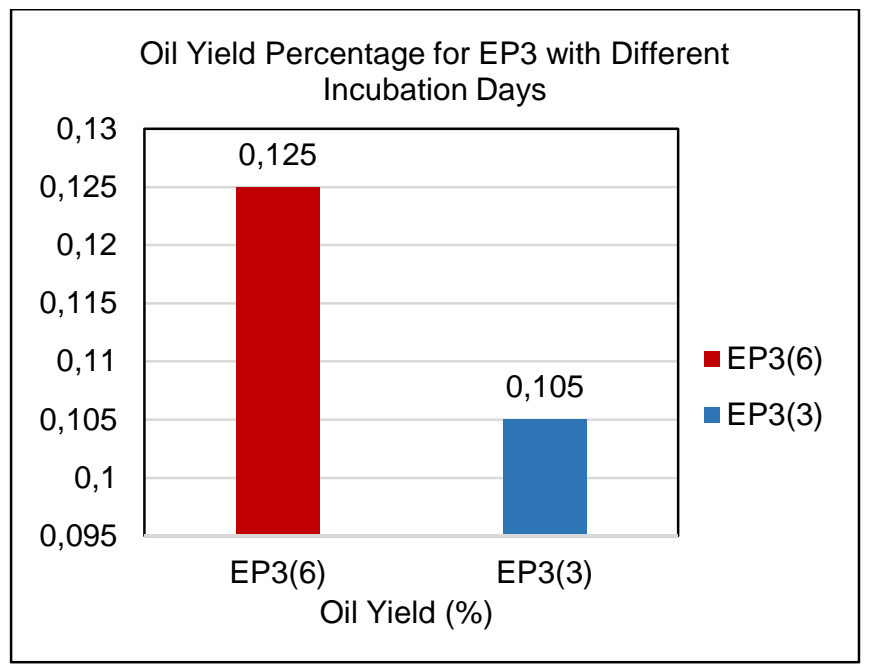

Fig. 3 Comparison on The Percentage of Agarwood Oil Yield for EP3 Samples with Incubation Days of 6 and three days.
Once the best enzyme concentration between 1, 3, and $5 \%$ have been met, the experiment was continued with reduced incubation time from 6 to 3 days for further investigation. As discussed previously, the best result obtained was from EP3, with the highest yield of $0.125 \%$ with an enzyme concentration of $3 \%$. EP3 (6) refers to sample incubated for six-day, and EP3 (3) is for sample incubated for three days. Figure 3 shows a comparison between EP3 (6) and EP3 (3) with an oil yield of $0.125 \%$ and $0.105 \%$, respectively. EP3 (3) with lower incubation time gives a lower percentage of agarwood oil yield as compared to that of EP3 (6). This shows that three days of incubation time cannot produce a better yield than six days. As mentioned previously, Jok et al. [22] stated in their study, where 14 days of soaking time produced the highest yield of oil as compared to 7 days for the sample with no pre-treatment. Thus, by further reducing the soaking day, the amount of oil yield becomes less significant.

TABLE I

SOME OF THE COMPOUNDS IDENTIFIED IN AGARWOOD ESSENTIAL OIL VIA GC-MS.

\begin{tabular}{|c|c|c|c|c|c|c|c|}
\hline \multirow{2}{*}{$\begin{array}{c}\text { Chemical } \\
\text { Compound }\end{array}$} & \multicolumn{7}{|c|}{ \% Of Total Area } \\
\cline { 2 - 8 } & S6 & S14 & EP1 & EP3 & EP5 & AO & EO \\
\hline Caryophyllene & 0.318 & 0.225 & 2.035 & 2.496 & - & 1.346 & - \\
\hline Valencene & 0.637 & 1.603 & 0.632 & 4.073 & 2.028 & 2.995 & 4.456 \\
\hline Gurjunene & - & 8.081 & 1.724 & 2.939 & - & - & - \\
\hline Aristolene & 1.256 & 1.884 & 1.198 & 2.218 & 2.009 & 3.202 & 2.152 \\
\hline Alloaromadendrene & - & 2.531 & 0.859 & 2.202 & 2.458 & - & - \\
\hline
\end{tabular}

\section{B. GC-MS on Chemical Compounds in Agarwood Oil} Extracted with Different Pre-treatment Method

The GC-MS analysis revealed a total of 335 compounds from all seven samples of agarwood oils. Some of the identified chemical compounds are tabulated in table I in the percentage of whole Essential Oil. The compositions of the compounds obtained differ with different pre-treatment method, which is supported by a study by Yoswathana [20]. Among the compounds found that contributes to the unique odor of agarwood oil are sesquiterpenes such as Caryophyllene, Gurjunene, Alloaromadendrene, and Gualene. However, some of the main compounds, such as jinkoh-eremol, epoxybulnesene, and $\beta$-agarofuran are missing from the results [27]. According to Chen et al. [28], different artificial methods used in stimulation the formation of the resin may produce different agarwood qualities which supported also by the study done Hashim et al. [29] which concluded that various factors may affect the different compositions of agarwood essential oil such as species/origin of the tree and methods of stimulation of agarwood resin.

From the table I, similar compounds can be seen increasing and decreasing depending on the different methods applied. Such as the percent total of Caryophyllene were notably increased in EP3 from $0.3 \%$ to around $2.0 \%$ but was missing in EP5 sample. Based on data obtained from the GC-MS analysis, Caryophyllene was identified in EP5, but the total area is too small, making it negligible. As previously mentioned, based on Terry and Heinrich [30] and
Tajuddin et al. [31], some of the compounds identified in the table, I provide the woody aroma to agarwood oil. Caryophyllene contributes to the spicy-wood aroma, while Gurjunene contributes to the woody balsamic aroma and Alloaromadendrene to the woody aroma. According to Hosni et al. [32], enzymatic pre-treatment led to an increase in the amounts of some of the compounds which may affect the aroma produced and eventually increase the yield of the essential oil. Compounds in Table I for EP3 shows an increase in the amount as compared to other samples but produced less Gurjunene from S14 which is also further supported by Hosni et al. [32] that enzymatic pre-treatment may induce a decrease of the compounds.

TABLE II

COMPARISON OF THE COMPOUNDS IDENTIFIED IN AGARWOOD ESSENTIAL OIL VIA GC-MS FOR EP3 (6) AND EP3 (3).

\begin{tabular}{|c|c|c|}
\hline \multirow{2}{*}{ Chemical Compound } & \multicolumn{2}{|c|}{ \% Of Total Area } \\
\cline { 2 - 3 } & EP3(6) & EP3(3) \\
\hline Caryophyllene & 2.496 & 0.075 \\
\hline Valencene & 4.073 & - \\
\hline Gurjunene & 2.939 & 0.531 \\
\hline Aristolene & 2.218 & - \\
\hline Alloaromadendrene & 2.202 & - \\
\hline
\end{tabular}

As for the EP3 (3) sample, only 17 compounds were detected from the GC-MS analysis. The percentage of the total area for the same compounds as the table I was tabulated in table II with comparison to EP3 sample that was 
incubated for six days. From table II, Caryophyllene and Gurjunene were among the main compounds identified for EP3 (3) with $0.075 \%$ and $0.531 \%$ as compared to EP3 (6) with $2.496 \%$ and $2.939 \%$ respectively. This showed that with reduced incubation time, fewer compounds could be extracted despite the enzymatic pre-treatment. This finding is in contrast with the research by Nor et al. [33] where there were no significant differences in the compounds found by GC-MS analysis with shaking time of 1,3 and 7 days but Boulila et al. [19] did mention in their study that enzymatic pre-treatment doesn't induce transformation to their samples' volatile compounds. This proved that longer soaking or incubation time than three days is necessary to extract all the compounds required even though the yield obtained is a considerable amount. There were no reported effects for agarwood compounds composition on soaking time less than five days with enzymatic pre-treatment [20], and Jok et al. [22] did research comparing the effect of different soaking time of $0,7,14,21$ and 28 days with no pre-treatment.

\section{Scanning Electron Microscope (SEM)}

The SEM micrographs were taken for all agarwood chips before hydrodistillation process. The images were captured at 500x magnification [22] as shown in figure 4, 5, 6, and 7. Figure $4(a, b)$ shows SEM captured images for untreated Agarwood chips clearly show that it has a smooth surface structure.
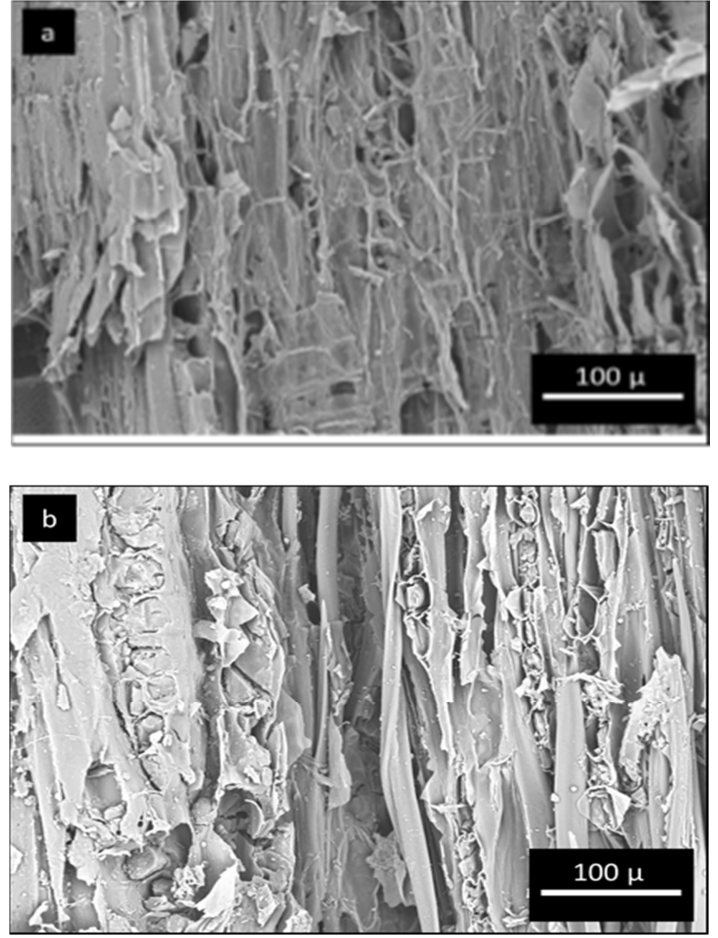

Fig. 4 Scanning Electron Microscopy (SEM) of Agarwood Chips before Hydrodistillation for Sample without Pre-treatment; a) S14; b) S6

For the enzymatic pre-treatment which used both acid and enzyme, figure 5 (c, d, e) showed that the outer layers were more disrupted and flakier surface structure caused by the removal of hemicellulose which contributes to the increase of oil yield for EP1, EP3 and EP5 as compared to S6 despite the similar soaking time. Figure 5 (d) showing the most disruption as compared to (c) and (e)
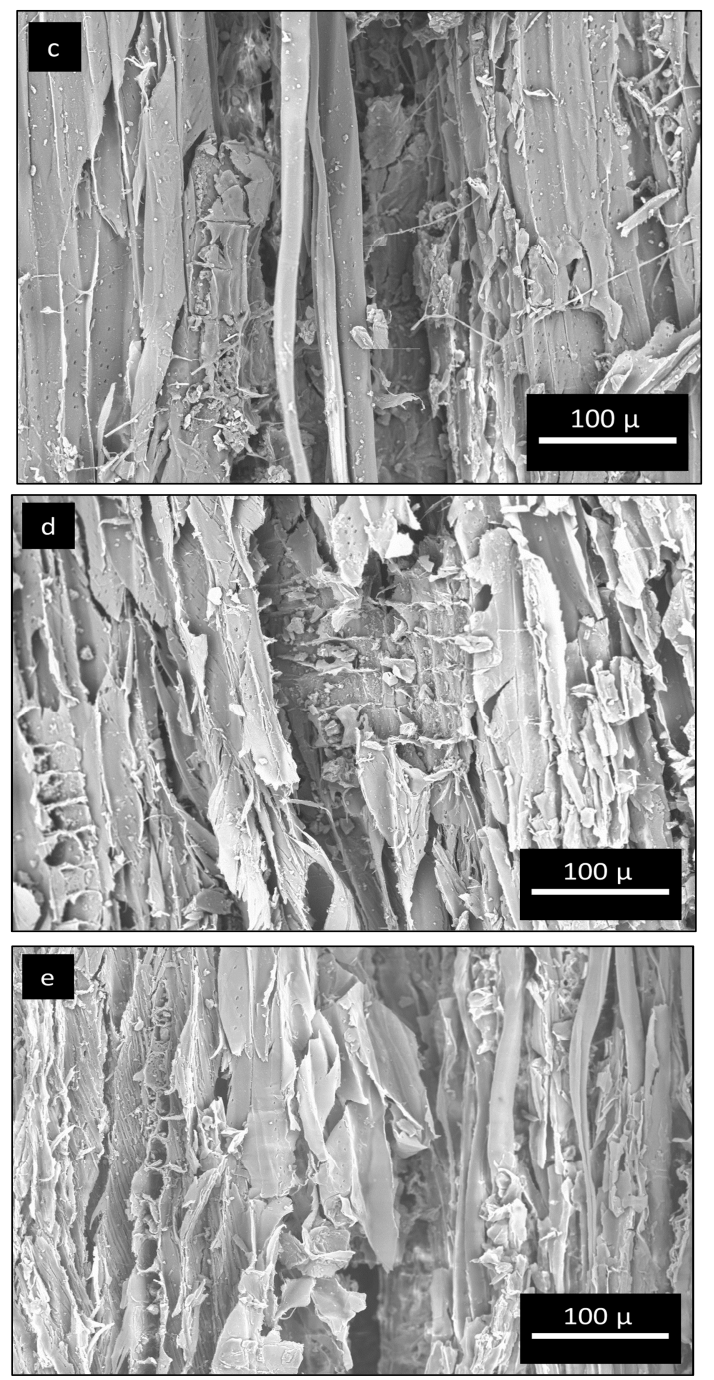

Fig. 5 Scanning Electron Microscopy (SEM) of Agarwood Chips before Hydrodistillation for Sample with Enzymatic Pre-treatment where c) EP1 d) EP3 and e) EP5.
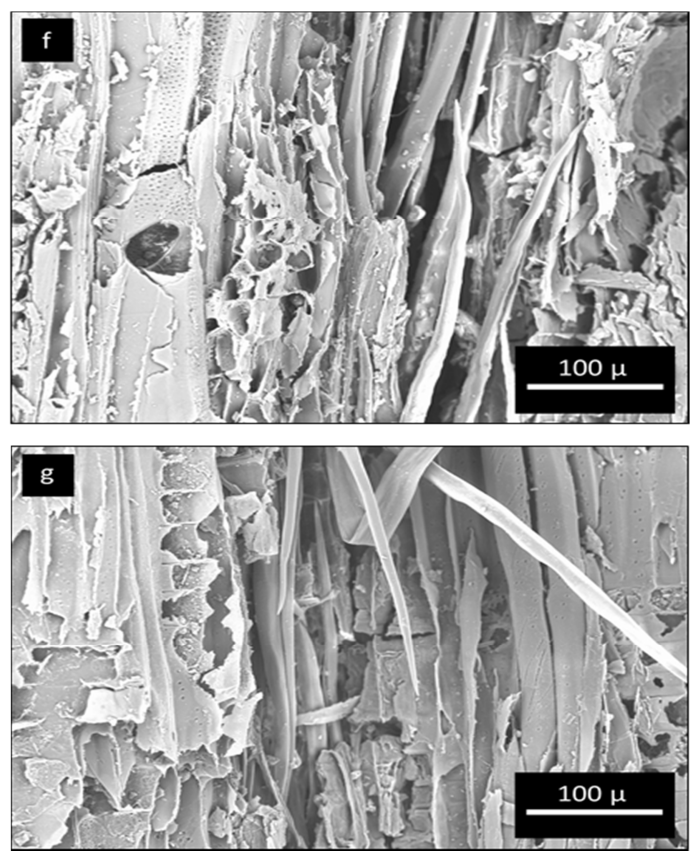

Fig. 6 Scanning Electron Microscopy (SEM) of Agarwood Chips before Hydrodistillation for f) AO and, g) EO 

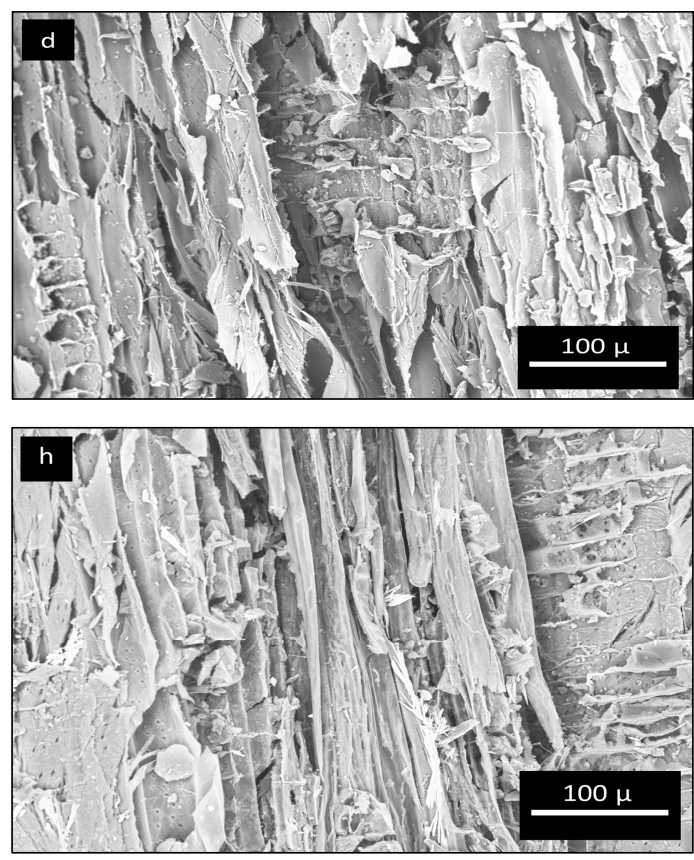

Fig. 7 Scanning Electron Microscopy (SEM) of Agarwood Chips before Hydrodistillation for EP3 with Different Incubation Days where d) EP3 (6) and h) EP3 (3)

The oil yield obtained from the sample in figure 5 (d) is $0.125 \%$, whereas the yield for sample in figure 5 (c, e) are $0.095 \%$ and $0.105 \%$ respectively. This showed that enzyme concentration of $3 \%$ is the optimal amount in extracting the essential oil of agarwood where the cellulose enzyme can digest more cellulose in the cell wall composition when the hemicellulose bonds were removed which was mentioned previously in $A$ for the effect of pre-treatment on agarwood oil yield [15], [25], [26]. Figure 6 (f, g) showed a much smoother and undisrupted surface compared to number 5 (d) where the oil yield obtained from these samples were $0.06 \%$ and $0.04 \%$ respectively. Samples with a combination of pretreatment from EP1, EP3, and EP5 has more yield of essential oil compared to AO and EO with EP3 having the highest yield. The alteration of the structure should be one of the reasons for the increase of enzyme accessibility towards cellulose during the hydrolysis, and this is by the findings reported by Chen et al. [28].

Figure 7 shows the comparison between agarwood chips that have undergone enzymatic pre-treatment with $3 \%$ enzyme concentration but with different incubation days of 6 and three days. Figure 7 (d) as previously discussed in figure 5 (d), has more disrupted and flakier surface structure but as for figure $7(\mathrm{~h})$, it has a rough surface structure but doesn't look as disrupted or flakier, and the oil yields obtained were $0.125 \%$ and $0.105 \%$ respectively. Fazila et al. [34] found that unsoaked sample produced $1.72 \%$ of oil yield as compared to sample soaked for seven days with sulfuric acid, which gave $6.78 \%$. They also mentioned that in previous studies, it showed that sufficient soaking could rupture the parenchyma cells thus enables the diffusion from the oil glands and this further clarifies the need of adequate soaking or incubation time for a more ruptured cell wall.

\section{IV.CONCLUSION}

The results of enzymatic pre-treatment on agarwood chips indicate that comparable yield is achieved even with a reduced soaking time of 6 days compared to standard 14 days soaking time. Optimum oil recovery was observed in the sample with $3 \%$ enzymatic pre-treatment with $0.125 \%$ oil yield. Common compounds identified using GC-MS were Caryophyllene, Gurjunene, Alloaromadendrene, and Gualene that make the unique agarwood's wood odor where Caryophyllene contributes to the spicy-wood aroma while Gurjunene contributes to the woody balsamic aroma and Alloaromadendrene to the woody fragrance. The aroma profile of pretreated agarwood oil has improved as compared to the standard. SEM results showed that the surface morphology of samples with enzymatic pretreatment was more disrupted and have flakier surface structure caused by the removal of hemicellulose which contributes to the increase of oil yield for enzymatic pretreated samples as compared to the standard sample despite the similar soaking time. Thus, enzymatic pre-treatment can likely be used in agarwood oil extraction with improved oil yield and less soaking time and with comparable oil quality.

\section{ACKNOWLEDGMENT}

The authors are grateful to Universiti Teknologi MARA, Malaysia for the research grant, 600-RMI/FRGS5/ (15/2015) and would like to express their gratitude to Biobenua Lojistik Sdn. Bhd. for the supply of agarwood chips.

\section{REFERENCES}

[1] S. Najafian, "Storage conditions affect the essential oil composition of cultivated Balm Mint Herb (Lamiaceae) in Iran," Ind. Crops Prod., vol. 52, pp. 575-581, 2014.

[2] D.-Y. Zhang, X.-H. Yao, M.-H. Duan, F.-Y. Wei, G.-H. Wu, and L. $\mathrm{Li}$, "Variation of essential oil content and antioxidant activity of Lonicera species in different sites of China," Ind. Crops Prod., vol. 77, pp. 772-779, 2015.

[3] D. P. De Sousa, "Bioactive Essential Oils and Cancer," Bioact. Essent. Oils Cancer, pp. 1-292, 2015.

[4] P. Costa, B. Medronho, S. Gonçalves, and A. Romano, "Cyclodextrins enhance the antioxidant activity of essential oils from three lamiaceae species," Ind. Crops Prod., vol. 70, pp. 341-346, 2015.

[5] M. R. Haji Che Daud and H. Hamdan, "Production and Chemical Compounds of Gaharu Extract by Using Supercritical Fluid Extraction (SFE) of Unsoaked Gaharu at Different Pressure," Adv. Mater. Res., vol. 1115, pp. 337-340, 2015.

[6] S. K. N. Afiffudden, H. Alwi, and K. H. K. Hamid, "Determination of 4'-hydroxyacetanilide in leaves extract of Aquilaria malaccencis by high pressure liquid chromatograph," Procedia - Soc. Behav. Sci., vol. 195, pp. 2726-2733, 2015.

[7] I. H. Burkill, W. Birtwistle, F. William Foxworthy, J. B. Scrivenor, and J. Gilbert Watson, A dictionary of the economic products of the Malay Peninsula. Published on behalf of the governments of Malaysia and Singapore by the Ministry of Agriculture and cooperatives. 1966

[8] T. Nakanishi et al., "Three Fragrant Sesquiterpenes of Agarwood*," vol. 23, no. 9, pp. 2066-2067, 1984.

[9] J. Alam et al., "An insight of pharmacognostic study and phytopharmacology of Aquilaria agallocha," J. Appl. Pharm. Sci., vol. 5, no. 8, pp. 173-181, 2015.

[10] D. T. Ahmaed, M. Mahmood, A. M. Masaad, and S. N. Tajuddin, "Investigation of Agarwood Compounds in Aquilaria malaccensis \& Aquilaria Rostrata Chipwood by Using Solid Phase Microextraction," Biomed. J. Sci. Tech. Res., vol. 1, no. 6, pp. 1-8, 2017 
[11] M. Mahfud, A. Chandra K. F., L. Qadariyah, and P. Prihatini, "Distillation Assisted by Microwave for Extracting Essential Oil from Java Cananga Flowers," Mod. Appl. Sci., vol. 9, no. 7, pp. 199205, 2015.

[12] M.-T. T. Golmakani and M. Moayyedi, "Comparison of microwaveassisted hydrodistillation and solvent-less microwave extraction of essential oil from dry and fresh Citruslimon (Eureka variety) peel," J. Essent. Oil Res., vol. 28, no. 4, pp. 272-282, 2016.

[13] M. Puri, D. Sharma, and C. J. Barrow, "Enzyme-assisted extraction of bioactives from plants," Trends Biotechnol., vol. 30, no. 1, pp. 3744, 2012.

[14] D. Rodrigues et al., "Impact of enzyme- and ultrasound-assisted extraction methods on biological properties of red, brown, and green seaweeds from the Central West Coast of Portugal," J. Agric. Food Chem., vol. 63, no. 12, pp. 3177-3188, 2015.

[15] K. C. Baby and T. V. Ranganathan, "Effect of enzyme pre-treatment on extraction yield and quality of cardamom ( Elettaria cardamomum maton .) Volatile oil," Ind. Crop. Prod., vol. 89, pp. 200-206, 2016.

[16] C. P. Passos, S. Yilmaz, C. M. Silva, and M. A. Coimbra, "Enhancement of grape seed oil extraction using a cell wall degrading enzyme cocktail," Food Chem., vol. 115, no. 1, pp. 48-53, 2009.

[17] J. Jiao et al., "Enzyme-assisted microwave hydro-distillation essential oil from Fructus forsythia, chemical constituents, and its antimicrobial and antioxidant activities," vol. 134, pp. 235-243, 2012.

[18] J. Chandran, K. Parukutty, P. Amma, and N. Menon, "Effect of Enzyme Assisted Extraction on Quality and Yield of Volatile Oil from Black Pepper and Cardamom," vol. 21, no. 6, pp. 1611-1617, 2012.

[19] A. Boulila et al., "Enzyme-assisted extraction of bioactive compounds from bay leaves (Laurus nobilis L.)," Ind. Crops Prod., vol. 74, pp. 485-493, 2015.

[20] N. Yoswathana, "Extraction of agarwood (Aquilaria crassna) oil by using supercritical carbon dioxide extraction and enzyme pretreatment on hydrodistillation," J. Food, Agric. Environ., vol. 11, no. 2, pp. 1055-1059, 2013.

[21] V. D. Dimaki, G. Iatrou, and F. N. Lamari, "Effect of acidic and enzymatic pretreatment on the analysis of mountain tea ( Sideritis spp.) volatiles via distillation and ultrasound-assisted extraction," J. Chromatogr. A, 2017.

[22] V. A. Jok, N. C. Radzi, and K. H. K. Hamid, "Agarwood Oil Yield As A Result of Changes in Cell Morphology Due To Soaking Process," Procedia - Soc. Behav. Sci., vol. 195, pp. 2443-2450, 2015.

[23] M. Bayram and A. Kaya, "Changes in properties of soaking water during production of soy-bulgur," J. Food Eng., vol. 61, pp. 221-230, 2004 .
[24] V. A. Jok, M. Arif, F. Zainudin, N. C. Radzi, and K. H. Ku "Compounds Identification in Agar Wood Soaking Water by Using GC-MS,” vol. 7, no. 5, pp. 340-343, 2016.

[25] Y. Chen, R. R. Sharma-Shivappa, D. Keshwani, and C. Chen, "Potential of Agricultural Residues and Hay for Bioethanol Production," pp. 276-290, 2007.

[26] J. S. Van Dyk and B. I. Pletschke, "A review of lignocellulose bioconversion using enzymatic hydrolysis and synergistic cooperation between enzymes - Factors affecting enzymes, conversion and synergy," Biotechnol. Adv., vol. 30, no. 6, pp. 14581480, 2012.

[27] P. Pripdeevech, W. Khummueng, and S.-K. Park, "Identification of Odor-active Components of Agarwood Essential Oils from Thailand by Solid Phase Microextraction-GC/MS and GC-O," J. Essent. Oil Res., vol. 23, no. 4, pp. 46-53, 2011.

[28] H. Chen, Y. Yang, J. Xue, J. Wei, Z. Zhang, and H. Chen, "Comparison of compositions and antimicrobial activities of essential oils from chemically stimulated agarwood, wild agarwood and healthy Aquilaria sinensis (Lour.) Gilg trees," Molecules, vol. 16, no. 6, pp. 4884-4896, 2011.

[29] Y. Z. .-Y. Hashim, N. I. Ismail, and P. Abbas, "Analysis of Chemical Compounds of Agarwood Oil From Different Species By Gas Chromatography Mass Spectrometry ( Gems )," IIUM Eng. J., vol. 15, no. 1, pp. 55-60, 2014.

[30] T. Acree and H. Arn, "Flavornet and human odor space, gas chromatography - olfactometry (GCO) of natural products," 1984. [Online]. Available: http://www.flavornet.org/.

[31] S. N. Tajuddin, C. M. Aizal, and M. M. Yusoff, "Resolution of Complex Sesquiterpene Hydrocarbons in Aquilaria malaccensis Volatile Oils Using Gas Chromatography Technique," in Agarwood: Science behind the Fragrance, R. MOHAMED, and Ed. Singapore: Springer Singapore, pp. 103-124, 2016.

[32] K. Hosni, I. Hassen, H. Chaâbane, M. Jemli, and S. Dallali, "Enzyme-assisted extraction of essential oils from thyme (Thymus capitatus L.) and rosemary ( Rosmarinus officinalis L .): Impact on yield , chemical composition and antimicrobial activity," Ind. Crop. Prod., vol. 47, pp. 291-299, 2013.

[33] N. A. Mat Yusoff, S. N. Tajuddin, A. Hisyam, and N. A. Mohd Omar, "Agarwood Essential Oil: Study on Optimum Parameter and Chemical Compounds of Hydrodistillation Extraction," J. Appl. Sci. Agric., vol. 10, no. 5, pp. 1-5, 2015.

[34] N. F. K and K. H. Ku Hamid, "Effects of soaking on yield and quality of agarwood oil,” J. Trop. For. Sci., vol. 24, no. 4, pp. 557564, 2012. 